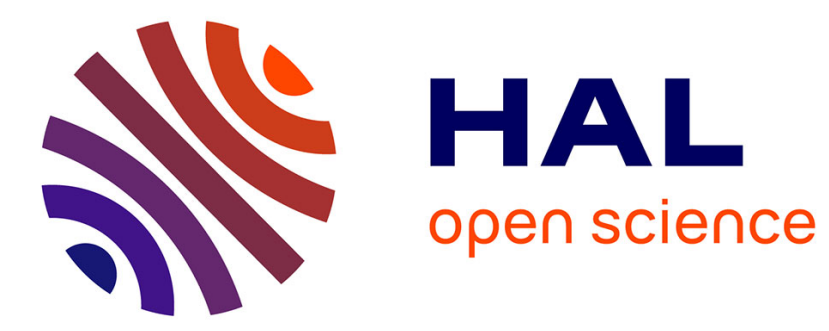

\title{
Role of intermediate species in the formation of ion tracks in PADC: A review
}

Michel Fromm, Satoshi Kodaira, Tamon Kusumoto, Rémi Barillon, Tomoya

Yamauchi

\section{- To cite this version:}

Michel Fromm, Satoshi Kodaira, Tamon Kusumoto, Rémi Barillon, Tomoya Yamauchi. Role of intermediate species in the formation of ion tracks in PADC: A review. Polymer Degradation and Stability, 2019, 161, pp.213 - 224. 10.1016/j.polymdegradstab.2019.01.028 . hal-03558134

\section{HAL Id: hal-03558134 \\ https://hal.science/hal-03558134}

Submitted on 4 Feb 2022

HAL is a multi-disciplinary open access archive for the deposit and dissemination of scientific research documents, whether they are published or not. The documents may come from teaching and research institutions in France or abroad, or from public or private research centers.
L'archive ouverte pluridisciplinaire HAL, est destinée au dépôt et à la diffusion de documents scientifiques de niveau recherche, publiés ou non, émanant des établissements d'enseignement et de recherche français ou étrangers, des laboratoires publics ou privés. 
See discussions, stats, and author profiles for this publication at: https://www.researchgate.net/publication/330678850

\section{Role of intermediate species in the formation of an energetic ion latent track in PADC: A review}

Article in Polymer Degradation and Stability · March 2019

DOI: 10.1016/j.polymdegradstab.2019.01.028

CITATIONS

27

5 authors, including:

Michel Fromm

University of Franche-Comté

138 PUBLICATIONS 1,859 CITATIONS

SEE PROFILE

7. REMI BARILLON

University of Strasbourg

85 PUBLICATIONS 1,340 CITATIONS

SEE PROFILE
READS

288

Satoshi Kodaira

National Institute of Radiological Sciences

203 PUBLICATIONS 1,236 CITATIONS

SEE PROFILE

Tomoya Yamauchi

Kobe University

124 PUBLICATIONS 1,525 CITATIONS

SEE PROFILE

Some of the authors of this publication are also working on these related projects:

Exposure of nanometre-scaled plasmid DNA layers to LEEs and plasmids exposed to USXs in aqueous media View project

The HIMAC project View project 
Accepted in Polymer Degradation and Stability, January 2019.

https://doi.org/10.1016/j.polymdegradstab.2019.01.028

\title{
Role of intermediate species in the formation of ion tracks in PADC: A review
}

\author{
Michel Fromm ${ }^{a}{ }^{*}$, Satoshi Kodaira ${ }^{b}$, Tamon Kusumoto $^{b}$, Rémi Barillon $^{c}$ and Tomoya \\ Yamauchi $^{\text {d }}$ \\ a Université de Bourgogne Franche-Comté, UMR CNRS 6249 Chrono-Environnement, 16 Route de Gray, 25030 \\ Besançon Cedex, France. \\ ${ }^{\mathrm{b}}$ Radiation Measurement Research Team, National Institute of Radiological Sciences, National Institutes for \\ Quantum and Radiological Science and Technology, 4-9-1 Anagawa, Inage-ku, 263-8555 Chiba, Japan \\ ${ }^{c}$ Institute Pluridisiplinaire Hubert Curien, 23 rue du Loess, 67037 Strasbourg, Cedex 2, France \\ ${ }^{\mathrm{d}}$ Graduate School of Maritime Sciences, Kobe University, 5-1-1 Fukaeminami-machi, Higashinada-ku, 658-0022 \\ Kobe, Japan
}

\begin{abstract}
This review paper intends at identifying the early processes arising during the formation of a latent ion track in Poly Allyl Diglycol Carbonate (PADC). We briefly summarize the physical and chemical processes specific to the description of the interaction of ionizing radiation with matter. Then we gather published information in relation to PADC response regarding energy absorption and further transient species formation. Emphasis is given to the chemistry of radicals. Due to a lack of available data in relation with clearly identified unpaired electron carriers in PADC, we use data stemming from surrogate molecules. Based on such data we suggest mechanisms for the decomposition of PADC during the early times of ion track formation. The $\alpha$-sites of ether functional groups in PADC appear undoubtedly as critical targets which during further decomposition behave as the most probable origin of Carbon dioxide release. All suggested mechanisms are multi-step processes. Combining different concepts and data in relation with the dynamics of transient species formed in the ion track of a polymer material, we propose that the effective track radius may be described as the radial extension of reactive species formed rather than the maximum distance at which $\delta$-rays escape out of ion's trajectory. Lastly, generalization of the different processes collected allows two major pathways to be proposed for describing the fate of damaged ether moieties in PADC. This way, evidence is given for a higher sensitivity of ether functional groups compared to ester carbonate ones. The latter generally being destroyed as a consequence of prior damaging of the ether group. Discussion presented here is of interest to the nuclear track community.
\end{abstract}

Keywords: PADC, Latent track, Free radicals, Track core \& penumbra, latent track dynamics.

Corresponding author. Université de Bourgogne Franche-Comté, UMR CNRS 6249 ChronoEnvironnement, 16 Route de Gray, 25030 Besançon Cedex, France.

E-mail address: michel.fromm@univ-fcomte.fr (M Fromm) 


\section{Introduction}

Poly allyl diglycol carbonate (PADC), often called CR-39 ${ }^{\mathrm{TM}}$ (for Columbia Resin\#39, a denomination proper to Columbia-Southern Chemical Corporation) is a glassy, transparent plastic with current and extensive use in the manufacture of eyeglass lenses. Besides, starting in 1978, PADC found seminal applications in the scientific field of nuclear tracks in solids, when two papers opened the way for profuse and promising applications $[1,2]$. Since these early years, PADC was used in numerous fields [3-5] and is still considered as an exceptional solid state nuclear track detector; notably due to a wide range of detectable energetic ions, a low energy threshold (even with low-LET protons) and high sensitivity [6-8]. As a passive particle track detector (PTD), PADC is a rather cheap laboratory consumable having conversely a large panel of possible applications. Chemical etching of the latent tracks is a sine qua non condition which allows ion tracks to be made visible, then analyzed and counted using a microscope [9]. PADC sensitivity (S) is hence linked to the etching step, more specifically to the difference between the specific track etch rate, $V_{T}$ (etch-rate of the damaged zone along and around the ion's trajectory called latent track) and bulk material's etching rate $\left(V_{B}\right)$. PADC sensitivity is defined as $S=\left(V_{T} / V_{B}-1\right)$, where $V_{T} / V_{B}$ represents the reduced etch-rate [10]. Nuclear track etching in PADC has been extensively studied, experimentally and theoretically [11-19], but although the proposed track-etching models generally well reproduce experimentally observed etched track shapes and dimensions, whatever are the proposed approaches, they don't explain why (and how) PADC has such good detection capabilities; notably when compared to other PTD materials. Starting in 1999 [20], with an Infra-Red spectroscopy study dealing with quantitative analyses of the chemical bonds broken by alpha particles in cellulose nitrate (LR115), an important effort has later been done in order to quantitatively describe chemical damages created in PADC (and other PTD polymers) by ionizing radiations [21-36]. Over that vast study, part of us (T. Yamauchi, T. Kusumoto \& R. Barillon) and their coworkers were able to highlight which are the chemical units of the PADC structure that are involved in the damaging process at the origin of a latent track. These studies are based on infrared spectral analyses of the loss (or appearance) of specific chemical functions further to polymer exposure to various ionizing radiations (ions, gamma rays). Chemical cross-section and G-values for breaking a given bond were provided along with a phenomenological model that includes Katz track-structure theory of delta-rays [37,38], notably via the concept of radial dose deposition across particle trajectories. The main achievements of this study are linked with a quantitative and a posteriori determination of the sensibility of PADC chemical functional groups to ionizing radiations expressed in terms of cross-sections and G-values for the loss of given chemical groups. Besides this study, it was also shown by others and further confirmed, that $\mathrm{CO}_{2}$ formation accompanies radiation damage [39-43]. Importantly, it has been proven experimentally that $\mathrm{CO}_{2}$ absorbed in the polymer material plays a sensitizing role (enhancement of the sensitivity $\mathrm{S}$ ) 
[44-50]. It has also been suggested that the hydroxyl groups generated by radio-oxidation, that decorate new end-points after ion irradiation might govern the track etching velocity due to their hydrophilicity $[34,51]$.

Primary energy deposition by ionizing radiation in matter is known to be an extremely fast process (requiring typically $10^{-18}$ seconds) [52] and constitutes the beginning of the physical phase ( $t$ $<10^{-15}$ seconds). For water radiolysis, it is generally considered that during the physicochemical phase $\left(10^{-15}-10^{-12}\right.$ seconds) secondary reactions arise, and later the chemical phase $\left(10^{-12}-10^{-6}\right.$ seconds) extends reaction processes up to the complete neutralization of the medium $[53,54]$. Altogether, this leads to the apparition of more or less stable molecular states in the latent track. Our feeling is that the physical chemistry and the chemistry of the time laps separating the physical phase from the moment where the detector is chemically etched is rather poorly described, yet it covers largely more than ten time decades. As mentioned by Zhu and coworkers [55]: "the energy deposition processes should be understood not only in a physical way but also in a chemical way". The aim of this paper consists in showing as precisely as possible what are the mechanisms involved when starting from the physical phase and going up to the establishment of the chemical equilibrium; in terms of radiation-induced chemical and/or radical intermediates.

\section{Polymerization and chemical etching of PADC}

Before going deeper into details with a description of the molecular damages suspected to take place in PADC further to ionizing radiation exposure, it might be relevant to first describe the polymerization process and the bulk polymer etching mechanism. PADC polymerization is initiated by radicals and proceeds via the addition of allyl groups resulting in a dense three-dimensional network (Figure 1, left) consisting of polyallyl chains joined by diethylene glycol dicarbonate links [56]. Polyallyl chains are the basic elements in the polymer network of PADC. As stated by Stejny [56], polymerization does not reach full conversion because the system enters the glassy state first. The residual mobility in the glassy state and the presence of chemically reactive groups are responsible for physico-chemical ageing of the polymer and the changes in the performance with time.

To the best of our knowledge, studying the way by which undamaged PADC is attacked (i.e. dissolved) by hot and concentrated bases in aqueous media, was first undertaken by Gruhn and coworkers [57], then by Tse et al. [58] and more recently by Kodaira et al. [59]. Overall, these three teams identify a same and unique bulk mechanism; namely that under the basic hydrolysis of the (carbonate-) ester moiety, hydroxide ions cause the scission of the (carbonate-) ester linkage. As a consequence, the PADC molecule degrades via cleavage of the carbonate ester linkage by the hydroxide ion to produce the carbonate ion and various organic etch products from whose diethylene glycol, ethylene glycol as well as polyallylalcohols are majority. The chemical reaction is 
summarized in Figure 1 (right-handed part). Importantly here, it should be pointed out that the bulk etching process depicted by $V_{B}$ involves that carbonate ions (and other mentioned organic species) are released in large quantities in the etching bath. In addition, it appears clearly that most of the organic fragments produced during the bulk etching process of PADC are organic alcohols.
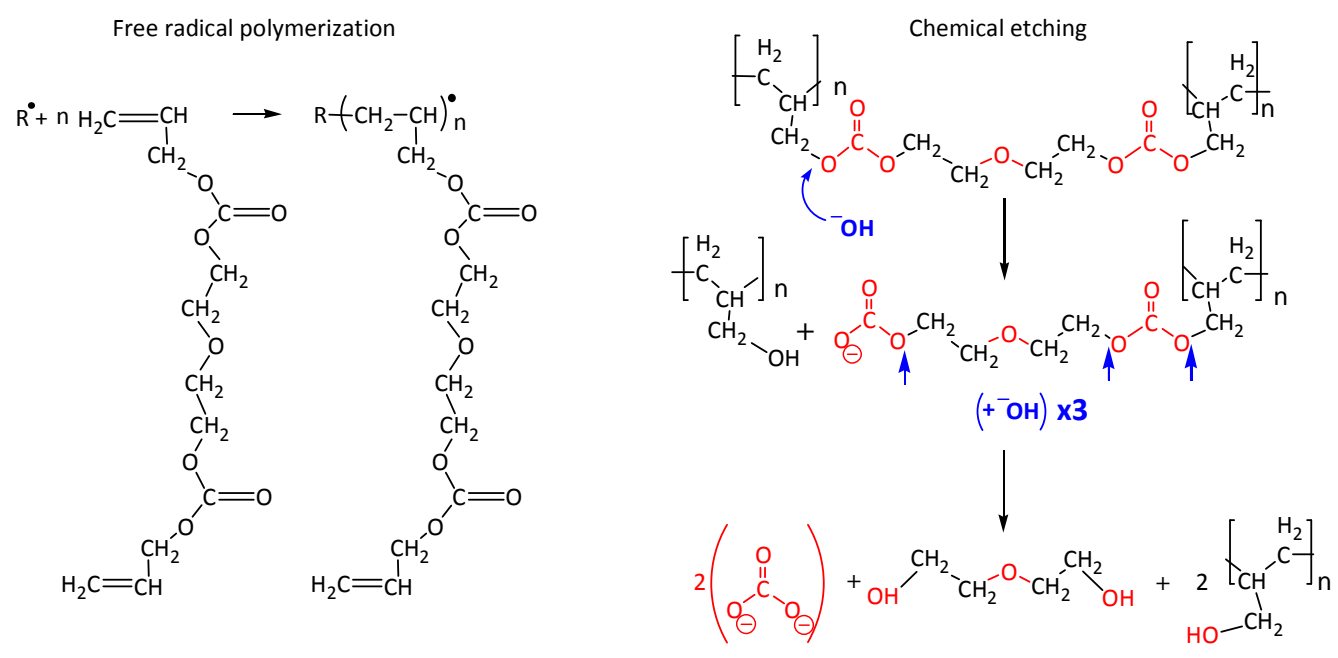

Figure 1: Summary of the radical polymerization process of PADC (left), after [56] and the basic hydrolysis of PADC carbonate-ester moieties by a hot and concentrated base (right), after [57-59]. On the right part, oxygenated functions are in red and hydroxyl ions in blue, for clarity.

It should also be noticed that the etching rate $V_{B}$ is of course temperature and concentrationdependent. Etching of PADC was largely analyzed and still is studied nowadays [60-69]. The main observed characteristic of the $V_{B}$ is an exponential dependence on both temperature and concentration of the etching bath. In the range of concentration between 4 and 10 mol. $\mathrm{L}^{-1}, \mathrm{~V}_{\mathrm{B}}$ is indeed satisfactorily described by an exponential dependence on $\mathrm{C}$ and $\mathrm{T}$. On the contrary, for concentrations higher than $10 \mathrm{~mol}^{-1} \mathrm{~L}^{-1}$, the bulk etch rate shows a smaller slope and the tendency towards saturation, obviously, cannot be described using a simple exponential dependence [69]. More refined models have to be developed when applied to both extreme (low and high) values of temperature and concentration. A possible way to ensure the convergence criteria for vanishing or extremely high values of concentration and temperature would be to use a factor or a free adjustable parameter which couples both external parameters T and C [69]. Using such a parameter was already suggested in an approach based on mathematical regressions [63] which didn't consider the physical chemistry of $\mathrm{V}_{\mathrm{B}}$ 's heterogeneous kinetics. It is worth noting that fitting procedures based on modified Arrhenius laws (in order to depict the chemical kinetics) provide a partial reaction order $\mathrm{S}$ as well as an activation energy, $E_{a}$. Experimentally determined values of $S$ are generally close to 2 and $E_{a} \sim 0.8$ $\mathrm{eV}$ [69 and references therein]. But it is important to recall that most of the approaches cited are based on laws related to homogeneous kinetics. Bulk etching of PADC is obviously a process of heterogeneous kinetics which hence requires a specific formalism which up to now remains unknown. 


\section{Electron impact on PADC}

\subsection{Physical stage}

The current paradigm of swift ion interaction with matter is that molecular damages created in a latent track are intimately related to the spatial distribution of ionization energy deposited by secondary electrons $[37,70]$. It should be noticed that we will not go more into details concerning the nuclear processes; those latter being confined to the tip of the latent track. Nevertheless as stated by Rana, Rutherford scattering may not have to be neglected in some cases [71]; physical damage in the incident particle latent track depends on the atomic composition of the target.

The physics of electron impact on molecular targets (here symbolized by $A B$ ) is nowadays rather well-described on a theoretical point of view (see Figure 2) [72]. However, the complete set of cross-sections associated to the different interactions of secondary electrons with large molecules like PADC still remains unknown. This is notably due to both theoretical and experimental challenges encountered when searching to determine such data for large molecules. As mentioned by others, electron impact dissociation of molecules poses severe challenges to theory [73]. As a consequence, except for the case of high-energy physics processes (nuclear reactions, fragmentation, ...), most of contemporary Monte-Carlo computer codes (MCNP, FLUKA, PENELOPE, GEANT4-DNA, ...) generally do not include other calculations than those related to processes 1, 2 and 5 of Figure 2 when the irradiated medium differs from water (the surrogate of biological media) $[74,75]$. Actually, due to the lack of cross sections for complex media such than PADC, the follow-up of secondaries and especially electrons is often stopped for rather large energy values in simulation codes [74-76]. Generally, calculations are performed for the water medium, and then scaled to the desired medium by using its exact mass density. Electron attachment resonances (process 9 in Figure 2) that lead to dissociation are general and prevalent at incident electron energies below $15 \mathrm{eV}$. Above $15 \mathrm{eV}$, dipolar dissociation (DD) processes generally start and increase with increasing energy. It has been shown that resonances survive in thin films and in the condensed phase [77]. It was shown recently that dependence of the mean energy of the secondary electron distribution along an ion trail versus ion's energy in PADC can be approximated by a monotonically increasing third order polynomial function [76]. 


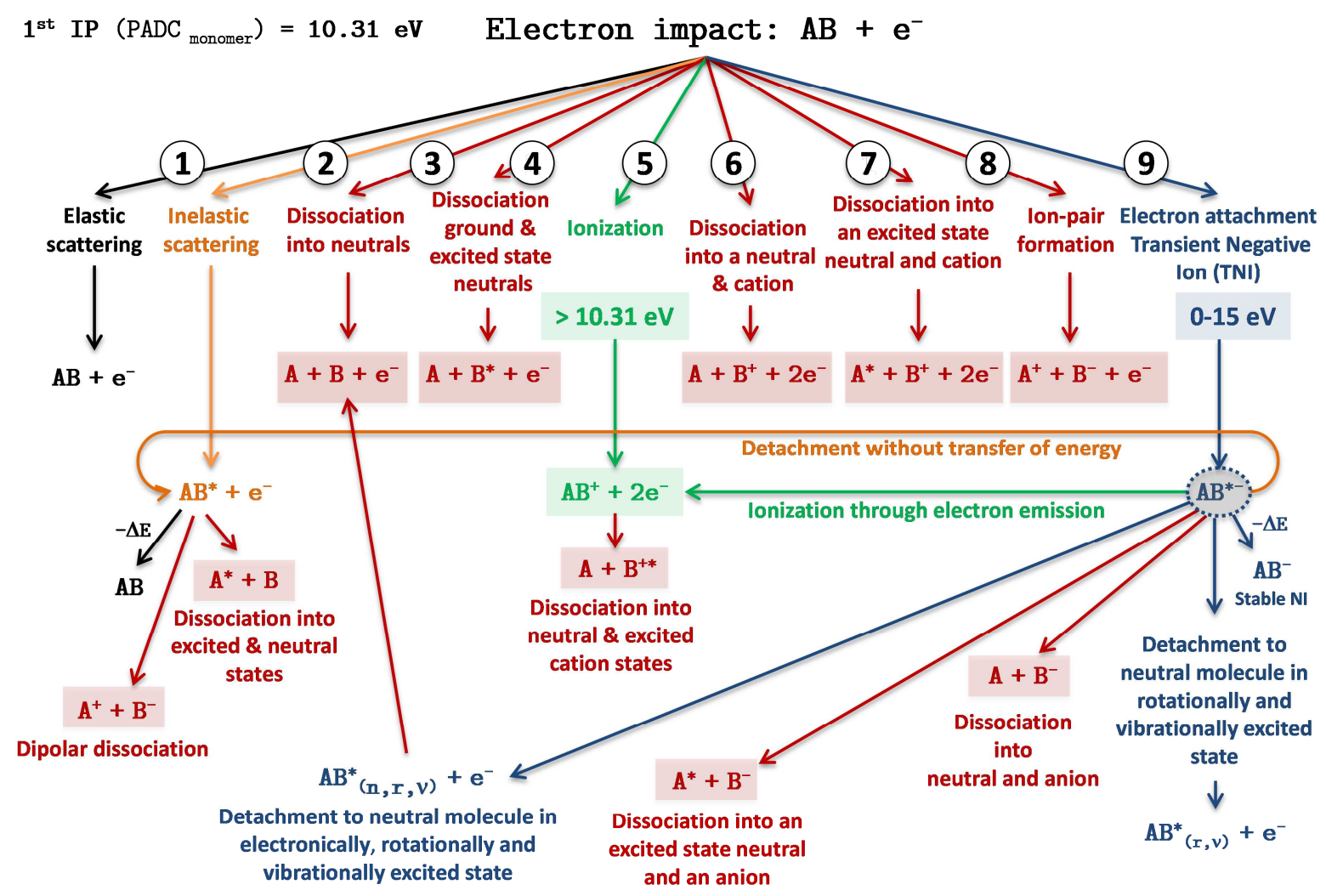

Figure 2: Possible processes that result from an electron collision with a target molecule, $A B$ (summarized using data and figures in [72] and [78]). Symbols $n, r$ and $v$ stand respectively for the electronic, rotational and vibrational quantum numbers for the excited states of $A B^{*}$. These processes belong to the physical phase of ionizing radiation interaction with matter.

In that study, a theoretical value of $10.31 \mathrm{eV}$ was computed for the $1^{\text {st }}$ Ionization Potential (IP) of the PADC monomer [76]. As an example, the mean energy of secondary electrons ejected along the path of $1 \mathrm{MeV}$ and $100 \mathrm{keV}$ protons in PADC were calculated to be equal to $41.2 \mathrm{eV}$ and $27.9 \mathrm{eV}$, respectively. The energy distribution of secondary electrons generated by an energetic swift ion in PADC drops in fact drastically down at low energies then follows a horizontal asymptote at the higher energies values; most of the secondary electron energies are thus low and much lower than the classical kinematic limit [76]. It appears actually useless to account only on current computer codes (i.e. in their present state) for describing the formation of a latent ion track in PADC in complete details. Moreover, all different interactions presented in Figure 2 constitute the physical stage of the latent track formation (i.e. without taking into account the various relaxation processes and chemical reactions that may take place further to primary energy deposition). That is why we will focus on experimental data in relation with the physicochemical and chemical stages of ionizing radiation interaction with polymer or organic molecules. 


\subsection{Physicochemical and chemical stages}

We present in Figure 3 a summary of the general processes leading to the formation of free radicals in polymers as suggested by Avan et al. [53]. Let us recall that a radical is an atom, molecule, or ion that has one or more unpaired valence electrons. In virtue of the Pauli Exclusion Principle, electrons form pairs with opposite spins which occupy an atomic or molecular orbital. So free radicals scavenge a given medium to seek out other electrons so they can become a pair. This causes molecular damage via a domino effect. At times $>10^{-12} \mathrm{~s}$, ion-radical intermediates are formed and react following the rules of radical chemistry. It should be mentioned that besides the well-known initiation-propagation-termination steps (see Figure 4), hydrogen abstraction (deprotonation) and $\beta$ scission rearrangements are major pathways [79] that lead to the formation of various chemical species inside a latent track.

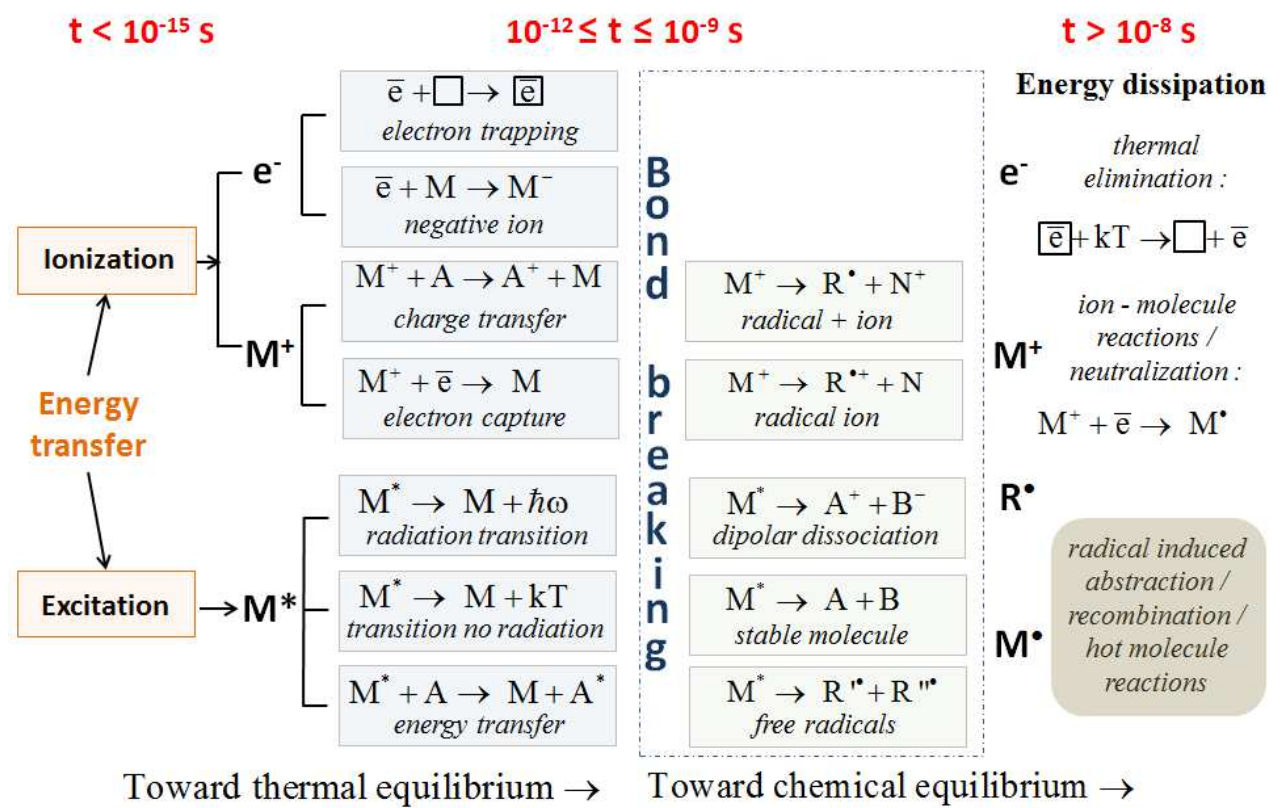

Figure 3: Formation and reactivity of free radicals in polymers exposed to ionizing radiations (summarized according to [53]).

In a $\beta$-scission reaction, the free radical breaks two carbons away from the radical carbon producing an olefin (ethylene) or a double bound (if the atom in $\beta$ position is a hetero-atom) and a primary free radical (see Figure 4 last line).

\subsubsection{Alkyl radicals and hydrogen radical.}

It is well-known that free radical stability decreases with increasing electronegativity of the radical atom. Closer is the partially unfilled orbital from the nucleus; the more unstable is the free radical. Thus, with only Hydrogen, Carbon and Oxygen in the chemical composition of PADC, alkyl radicals $\left(R-C^{\circ} H-R^{\prime}\right)$ should be considered as prevalent during the initiation step (they may be seen as 
major precursors). In that sense, release of $\mathrm{H}^{\bullet}$ (and further possible $\mathrm{H}_{2}$ formation) is seen as a regular process in the vast majority of polymer irradiation studies [52]. As a consequence, crosslinking, alkene and alkyne formation are considered as prevalent processes in the latent track formation of polymers, especially aliphatic ones that are partially or totally saturated [52]. We present in Figure 4 the summary of reactions through which alkyl and hydrogen radicals are involved when alkanes are exposed to ionizing radiations [80].

$$
\begin{aligned}
& \mathrm{R}-\mathrm{CH}_{2}-\mathrm{CH}_{2}-\mathrm{R}^{\prime} \underset{\text { (initiation) }}{\stackrel{\text { Radiation }}{ }} \mathrm{H}^{\bullet}+\mathrm{R}-\mathrm{CH}_{2}-\dot{\mathrm{C}} \mathrm{H}-\mathrm{R}^{\prime} \\
& \left.\begin{array}{rrr}
\mathrm{H}^{\bullet}+\mathrm{R}-\mathrm{CH}_{2}-\mathrm{CH}_{2}-\mathrm{R}^{\prime} & \stackrel{\text { abstraction }}{\longrightarrow} & \mathrm{H}_{2}+\mathrm{R}-\mathrm{CH}_{2}-\dot{\mathrm{C}} \mathrm{H}-\mathrm{R}^{\prime} \\
\mathrm{R}-\mathrm{CH}_{2}-\dot{\mathrm{C}} \mathrm{H}-\mathrm{R}^{\prime} & \text { transfert } & \mathrm{R}-\mathrm{CH}_{2}-\mathrm{CH}-\mathrm{R}^{\prime} \\
\mathrm{R}-\mathrm{CH}=\mathrm{CH}-\mathrm{R}^{\prime} & \text { cross link } & \mathrm{R}-\dot{\mathrm{C}} \mathrm{H}-\stackrel{\mathrm{C}}{\mathrm{C}}-\mathrm{R}^{\prime}
\end{array}\right\} \text { (propagation) }
\end{aligned}
$$

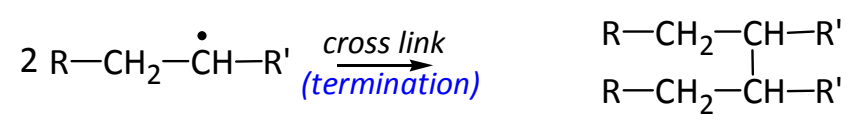

$$
\begin{aligned}
& 2 \mathrm{R}-\mathrm{CH}_{2}-\dot{\mathrm{C}} \mathrm{H}-\mathrm{R}^{\prime} \stackrel{\text { (termination) }}{\longrightarrow} \mathrm{R}-\mathrm{CH}=\mathrm{CH}-\mathrm{R}^{\prime}+\mathrm{R}-\mathrm{CH}_{2}-\mathrm{CH}_{2}-\mathrm{R}^{\prime} \\
& \mathrm{H}^{\bullet}+\mathrm{H}^{\bullet} \stackrel{\text { (termination) }}{\longrightarrow} \mathrm{H}_{2} \\
& \mathrm{H}^{\bullet}+\mathrm{R}-\mathrm{CH}_{2}-\dot{\mathrm{C}} \mathrm{H}-\mathrm{R}^{\prime} \underset{\text { (termination) }}{\stackrel{\text { abstraction }}{\longrightarrow}} \mathrm{H}_{2}+\mathrm{R}-\mathrm{CH}=\mathrm{CH}-\mathrm{R}^{\prime}
\end{aligned}
$$

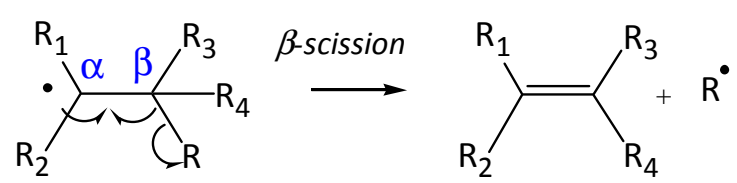

Figure 4: Formation and reactivity of alkyl and hydrogen free radicals on the methylene chains of PADC (summarized according to $[80,81])$. In the last line, the general mechanism of a $\beta$-scission reaction is shown (in the case where no heteroatom is present).

Propagation of radicals arises via hydrogen abstraction and crosslinking. It is important here to check again the general (but condensed) formula of PADC polymer (Figure 1). Indeed, two different types of methylene chains exist in PADC; namely those stemming from the polymerization process and those inserted between the central ether function and a carbonate moiety. The latter is a linear chain as the former includes a tertiary carbon resulting from polymerization. It is well-known from organic chemistry that stability of carbon radicals is as follows:

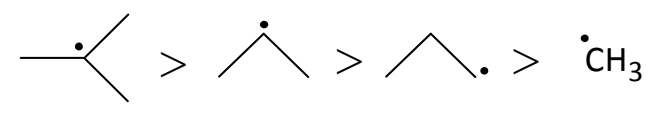

By virtue of the following statement; the more stable the free radical that is left behind, the weaker will be the $\mathrm{C}-\mathrm{H}$ bond strength $\left(\mathrm{C}-\mathrm{H}\right.$ bond strengths: $\left.\mathrm{CH}_{4}>\mathrm{R}-\mathrm{CH}_{3}>\mathrm{R}-\mathrm{CH}_{2}-\mathrm{R}>\mathrm{R} 3 \mathrm{C}-\mathrm{H}\right)$. The fate of alkyl radicals in PADC in relation with their position on the polymer chain will be discussed later on in 
this article. A study performed during the polymerization stage of ADC monomer surprisingly evidenced that the allyl radical $\left(\mathrm{CH}_{2}=\mathrm{CH}-{ }^{\circ} \mathrm{CH}-\right)$ may survive at least 6 months [82]

\subsubsection{Carbonate radicals.}

The ion-radical intermediate created by ionization of organic carbonates is shown in Figure 5, this radical undergoes a rapid internal proton capture via formation of a six-member ring transition state [83]. In Figure 5, the first line stems from a study in which radical intermediates produced from organic carbonates (especially dimethyl and diethyl carbonates) in low-temperature matrices were investigated by electron paramagnetic resonance (EPR) spectroscopy along with quantum-chemical calculations [83]. Irradiation was provided by $32 \mathrm{keV} \mathrm{X-rays.} \mathrm{The} \mathrm{second} \mathrm{line} \mathrm{of} \mathrm{reactions} \mathrm{in} \mathrm{Figure} 5$ is composed of two very common processes in radical chemistry, namely deprotonation and successive $\beta$-elimination. These mechanisms are suggested because the release of $\mathrm{CO}_{2}$ was clearly identified in several experimental studies related to PADC exposure to ionizing radiations [39-43]. Interestingly the same scheme as proposed in the first line of Figure 5, was identified by others, using gamma irradiation of aliphatic esters kept at 77K [84]. The six-member ring transition state shown in the upper-side of Figure 5 is also in agreement with the interpretation suggesting reaction of hydrogen transfer given by others for organic carbonates [85].

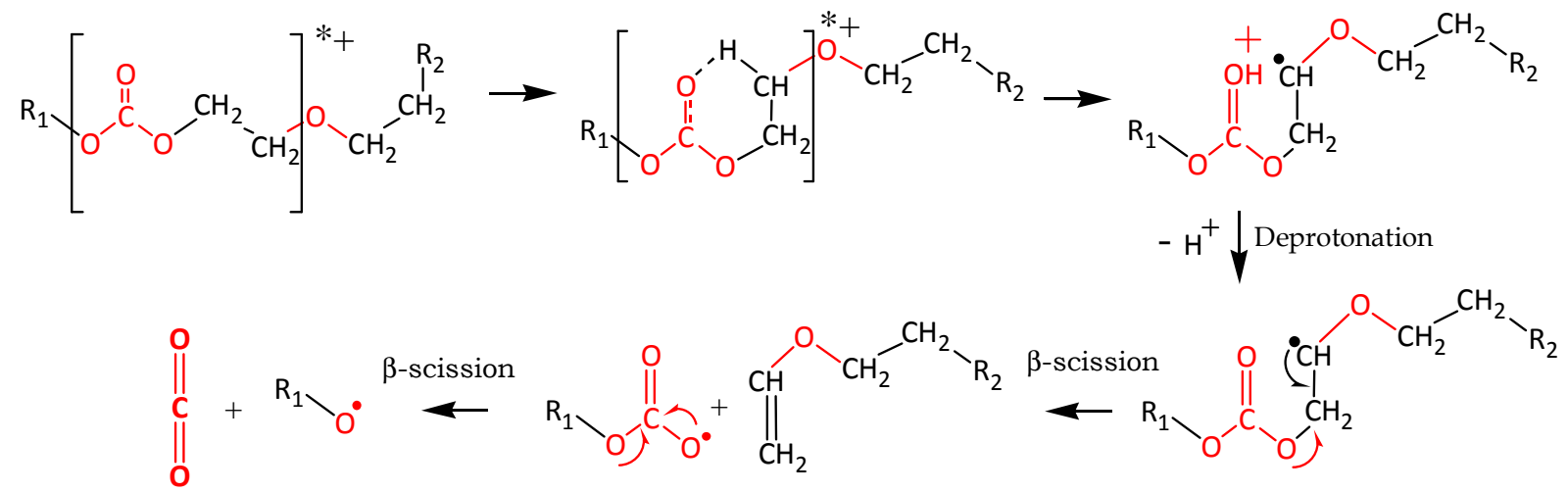

Figure 5: First (upper) line is for the positive ion-radical intermediate identified at 77K for ionization of dimethyl and diethyl carbonates irradiated by X-rays [83] which was here transposed to the comparable PADC structure. The second line illustrates how carbon dioxide can be a stable product following usual decomposition pathways of the chemistry of radicals.

Lastly, the mechanism by which, after rearrangement, one of the oxygen atoms of the carbonate moiety carries an unpaired electron and then decays to form $\mathrm{CO}_{2}$ was already suggested for PADC, $[86,87]$. As already mentioned, generation of $\mathrm{CO}_{2}$ in irradiated PADC was observed [39-43] as well as formation of $\mathrm{CO}$ and $\mathrm{H}_{2}$ [39]. $\mathrm{CO}_{2}$ yields were experimentally determined for PADC exposed by 130 MeV C-13 ions [42]. 
Concerning now the decomposition pathways of a negative carbonate ion-radical intermediate, such unstable species was actually identified at $77 \mathrm{~K}$ in radiation-chemical transformations of ethylene carbonate, the mechanism is transposed to PADC in Figure 6.

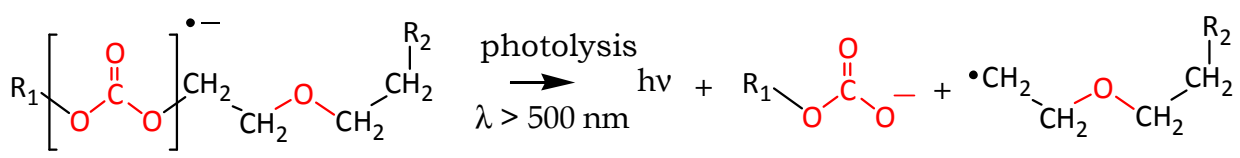

Figure 6: Photolytic decomposition of the negative ion-radical intermediate identified at 77K for organic carbonates [73] transposed to PADC

Reaction products in Figure 6 are for the first one (the carbonate anion) a stable specie and for the second one, an unstable compound subject to further decomposition or reaction ( $\beta$ elimination might notably release ethylene a common product of polymer radiolysis, not shown here). The mechanism presented in Figure 6 was confirmed as well by others for polyesters [84]. Decomposition of the negative ion-radical intermediate of an organic carbonate does not destroy the carbonate moiety, IR spectroscopy analyses would at least be reflected in a shift of the $\mathrm{C}=\mathrm{O}$ and ester absorption lines.

\subsubsection{Ether radicals.}

In experiments involving ethers, several aliphatic ethers (Polymethylene oxide, polypropylene oxide, poly-n-butylene oxide), were sealed under high vacuum in quartz tubes and irradiated at $77 \mathrm{~K}$ using ${ }^{60} \mathrm{Co}$. Then formation of a positive ether ion-radical intermediate was identified by electron spin resonance (ESR) [88], see Figure 7. It is noteworthy here to mention that the counter-intuitive process of Carbone dioxide production initiated by a positive ether ion-radical intermediate is finally much more likely to happen than the one stemming from the primary decomposition of a positive carbonate ion-radical intermediate (Figure 5). There are indeed much more pathways leading to $\mathrm{CO}_{2}$ formation when starting from ether ion-radical rather than from a carbonate ion-radical. 


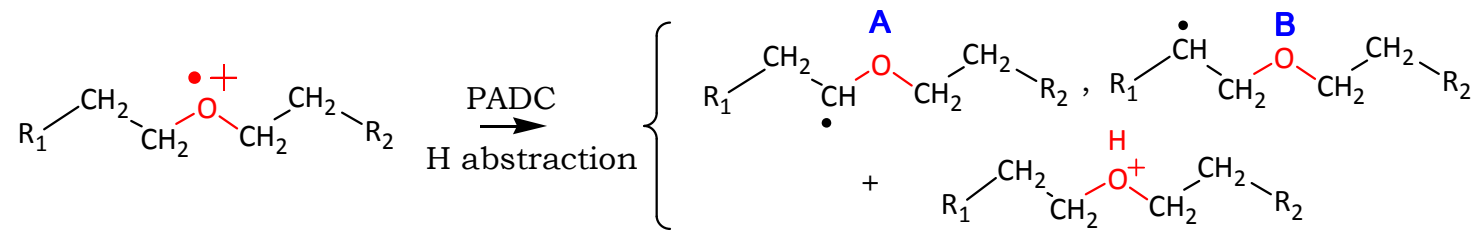

C

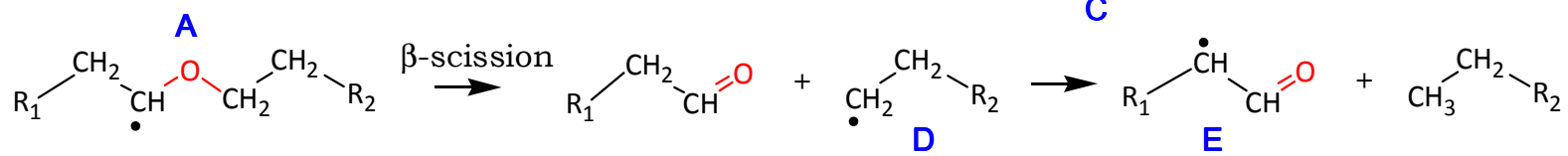

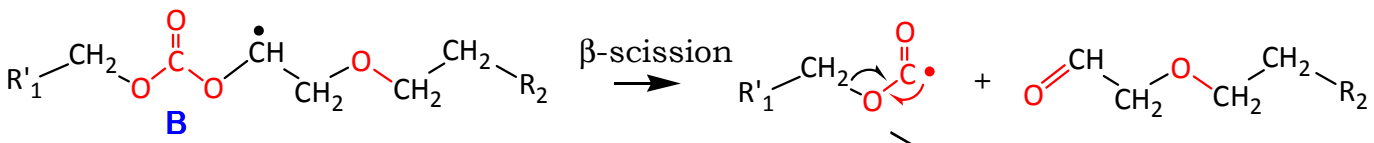<smiles>[R17]CCC</smiles>

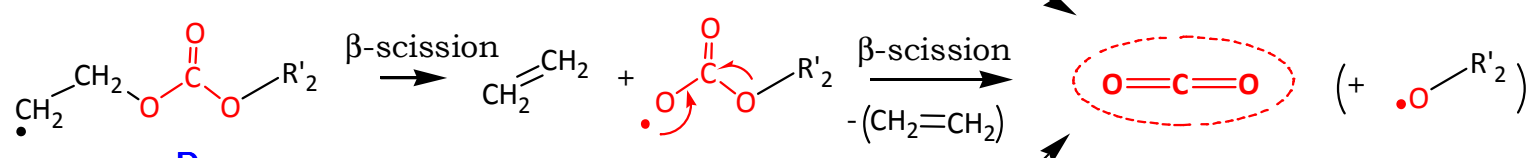

D

$$
-\left(\mathrm{R}_{1}{ }_{1}-\dot{\mathrm{C}} \mathrm{H}_{2}\right)
$$<smiles>[R1]COC(=O)O[C](C)C=O</smiles>

E

Figure 7: Formation of a positive ether ion-radical intermediate by gamma-irradiation as observed with several types of organic ethers [88]. The general scheme proposed is here transposed to the ether function of PADC. We show that the $\beta$ scission process of products $\mathrm{B}, \mathrm{D}$ and $\mathrm{E}$ all are likely to generate $\mathrm{CO}_{2}$ gas (all possible pathways are not shown). Besides, byproducts are stable aldehydes and instable oxygen radicals which might further decompose or react in the medium.

Potential precursors of $\mathrm{CO}_{2}$, namely radicals similar to $\mathrm{B}$ and $\mathrm{E}$ (Figure 7) also have been identified in poly(methyl methacrylate) (PMMA) exposed to electrons [89]. It should be mentioned that in PMMA the ester function(-CO-O-) is present instead of the carbonate moiety (-O-CO-O-). Chang and Laverne [90] analyzed the gaseous products of the gamma and heavy-ion radiolysis of PMMA. As mentioned by these authors, the radiolytic production of $\mathrm{H}_{2}$ and $\mathrm{CH}_{4}$ is mainly from the abstraction reactions between appropriate radical precursors and $-\mathrm{CH}_{2}-$ chain units. They have shown that the $G$ values (radiolytic yields) for all the gases increase slightly with increasing LET up to about $80 \mathrm{eV} / \mathrm{nm}$, then rise rapidly with further increases in LET. Their analysis suggests that the decomposition of the ester group radical $\left({ }^{\circ} \mathrm{COOCH}_{3}\right)$, better called methyl carboxylate radical, is responsible for the production of $\mathrm{CO}$ and $\mathrm{CO}_{2}$ (see also references therein) and besides that reaction mechanisms related to gas production are strongly influenced at high LET.

The methyl carboxylate radical also was invoked as a precursor while $\mathrm{CO}$ and $\mathrm{CO}_{2}$ are formed in electron-irradiated PMMA [91]. Kinetic curves and kinetic constants for their formation were derived from analyses of electron-induced degradation in PMMA and the following mechanism was 
suggested (Figure 8). Unfortunately, transposition to PADC is here complicated by the difference existing between ester and carbonate moieties. However, it appears that the decomposition products of compounds $\mathrm{B}$ and $\mathrm{E}$ (Figure 7), which themselves decay into $\mathrm{CO}_{2}$, are analogous to the carboxylate radical presented in Figure 8 (see center of the figure); thus strongly reinforcing the reactions proposed herein.

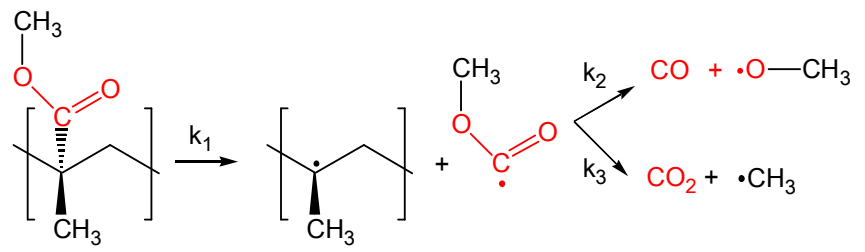

Figure 8: Photolytic decomposition of the negative ion-radical intermediate identified at 77K in organic carbonates [91].

We identify thus at least four pathways leading to the formation of Carbone dioxide, three of them stemming from the rearrangement of the positive ether ion-radical intermediate, the fourth pathway involves the formation of a carbonate ion-radical intermediate. It is clear that other pathways may exist, notably those in relation with the formation and further decay of a transient negative ion at low electron energies (Dissociative electron attachment, process 9 of Figure 2 ) and those in relation with pathways 3, 4, 6 and 7 of Figure 2. As far as we are aware, those pathways are not presently identified experimentally. At this stage though, one thing is clear, the succession of secondary reactions arising in the latent track release gases $\left(\mathrm{H}_{2}, \mathrm{CO}_{2}, \mathrm{CO}, \ldots\right)$ and form free radicals as well as new chemical moieties; notably aldehydes, alcohols and alkenes.

\section{Chemical composition of the latent track.}

\subsection{Radial extension of the latent track - the role of free radicals.}

The frequently-used definition of track core and track halo (alternatively called track penumbra) [92] is that: "ions typically deposit a large fraction of their energy in a small (cylindrical) region so-called core of the track. Heavy ions cause the release of electrons denoted as delta-rays and the outer region of these tracks is often called the penumbra". Let us recall that a delta ray is a secondary electron with enough energy to escape a significant distance away from the primary radiation beam and produce further ionization. This is the physics point of view, namely a description that only takes into account the physical stage (for more details the reader is invited to acquaint with some of the seminal studies on that topic [93-95] and references therein). In order to avoid misunderstandings, the penumbra radius $\left(r_{p}\right)$ should be defined as $r_{p}=r_{t}-r_{0}$, where $r_{t}$ is the total latent track radius (often called effective track radius) and $r_{0}$ is the track core radius. In the present 
paper, we are focusing on the physicochemical and chemical stages, during which free radicals can migrate and thus recombine or propagate. A question that arises concerns the ability (or not) of free radicals to diffuse away from the track core, or even possibly far away from the physical penumbra during the physicochemical phase. Due to their relative mobility and reactivity, free radicals are indeed prone to migrate; they may thus enlarge the physical track penumbra (the damaged zone described based on the sole action of delta-rays). This aspect was especially analyzed experimentally by quantifying the spatial distribution of damages caused by a single ion around its path, thus by determining the radial distribution of free radicals produced in cellulose triacetate (CT) [96]. CT contains ester and cyclic ether functions. That former original approach was done by using the scavenger technique combined with visible spectroscopy as well as statistical analyses. The authors based their analyses on the concepts of track core and track penumbra and estimated radii in the conceptual framework of experimentally-determined radial distributions of free radicals around an ion's path. The track core radii varied from [0.01 - 0.2] $\mathrm{nm}$ to [0.5 - 2] $\mathrm{nm}$ depending respectively on light (protons or alpha-particles) or heavier ions (Carbon and Argon) irradiations in the energy range of respectively [8 - 1] MeV.amu ${ }^{-1}$. These authors claimed that "...for light ions ( $\mathrm{H}$ and $\mathrm{He}$ ), the values of track core radii are similar to inter-atomic distances; showing that track core has no real physical meaning for these ions". Later on, another group proposed a model [97] which makes it possible to simulate the early time evolution of hydrogen radicals which form molecular hydrogen by recombination in a single track following ion irradiation of polymers. Interestingly, this model makes it possible to compute the density profile of residual carbon along the ion track. In other words the radial variation of hydrogen radical $\left(\mathrm{H}^{*}\right.$, considered as a copiously released radical upon polymer irradiation and having superior reduction ability) along with $\mathrm{H}_{2}$ radial profiles, residual $\mathrm{C}-\mathrm{H}$ and newly formed C-C bond (crosslinking) concentrations can be computed as a function of radial distance to ion's trajectory. The model was applied to PE (Polyethylene), PS (Polystyrene, containing one phenyl ring per pattern) and PC (Polycarbonate, containing two phenyl rings per pattern) exposed to $\mathrm{He}, \mathrm{Ne}$ and $\mathrm{Ar} \mathrm{MeV-ions} \mathrm{[97].} \mathrm{A} \mathrm{general} \mathrm{trend} \mathrm{observed} \mathrm{when} \mathrm{irradiating} \mathrm{with} \mathrm{He}, \mathrm{Ne}$ and $\mathrm{Ar}$ ions is that while both residual $\mathrm{C}-\mathrm{H}$ and newly formed $\mathrm{C}-\mathrm{C}$ bonds keep the same proportions up to a given radial distance, for larger radial distances, $\mathrm{C}-\mathrm{H}$ start to increase as $\mathrm{C}-\mathrm{C}$ bonds decrease, both finally reaching plateau values (i.e., the pristine concentrations of undamaged material). Diffusion of $\mathrm{H}^{\bullet}$ away from the track center causes a reduction there of the original carbon-hydrogen (C-H) bonds [97]. Using the model, radial profiles for crosslinked bonds (C-C) in PS have been predicted to reach typically $5 \mathrm{~nm}$ distance aside particle's trajectory. These authors also determined effective radii of latent tracks for 1.5 MeV alpha particles and O ions in PS which had values of $3.8 \mathrm{~nm}$ and $6.6 \mathrm{~nm}$, respectively [97]. In comparison, Vareille and coworkers [96] determined an effective track radius of $3.7 \mathrm{~nm}$ for $1.5 \mathrm{MeV}$ $\mathrm{O}$ ions in CT. Because PS and CT present noticeable differences in their chemical composition 
(especially the presence of an aromatic ring in the PS structure which has radio-resistant properties), it is tough comparing effective track radii. It should be noticed that when transforming an experimental bond breaking cross section in a track radius [27-29], the obtained track radius depends on the type of chemical modification under consideration. Such track radii should therefore constitute approximate data, namely effective scaling data rather than absolute values. Interestingly, in compliance with earlier studies performed by Apel et al. and by Tombrello [98,99], an observed invariant in all mentioned studies is the increase of experimentally-determined latent track radii with LET. Within the same PADC polymer target, using a variety of ions at identical LETs, depending on the chemical function analyzed by IR spectroscopy, experimentally-determined track radii appear to be quite different [27]. Effective track radii for ether bonds are also found to be systematically larger than those determined for carbonate ester bonds and $\mathrm{CH}$ groups, those two latter remaining always quasi-similar at fixed LET value (this observation stands also for the respective G-values and removal cross-sections). Overall, such observation militates in favor of the special case of the ether function being the most radio-sensitive function in PADC; or that in other words it may appreciably be damaged in the "outer-part" of the latent track (penumbra). In a first glance, it seems not obvious that delta-rays would preferentially damage ether functions on wider radial distances from the ion's trajectory than other chemical functions (i.e. carbonate ester bonds and alkyl groups). Or at least, ether functions may be more sensitive to the low-energy secondary electrons (0-15 eV - not $\delta$-rays), especially those produced within the end of short tracks where energies drop to the electron-Volt scale. This is physics reasoning, switching to chemistry, another situation might be considered; namely that the diffusion of light free radicals (especially $\mathrm{H}^{*}$ ) out of the track core should preferentially affect ether functions. Among known radiosensitive groups in polymers, those including an hetero-atom $\left(\mathrm{O}\right.$, halogen, ...) and those presenting unsaturation $\left(\mathrm{R}-\mathrm{C}=\mathrm{C}-\mathrm{R}^{\prime}\right)$ are the most sensitive to ionizing radiations, on the contrary, substantial intramolecular protective effect by phenyl ring groups in polymers was demonstrated [100]. The final shape and dimensions of the latent track may thus be the consequence of one or the other of physical or (physico-) chemical processes (especially free radical mobility) or possibly both of them as they constitute temporally distinct but successive stages. It is in particular well established that when an organic molecule is ionized, the charge can migrate within the molecule, so both free-radical and molecular rearrangement processes finally play part in the reaction mechanism [101]. Extremely important and well-established is the fact that reaction of a hydrogen radical (a free radical with high mobility and reactivity) on ether containing molecules produces $\alpha$-site radicals $\left(\mathrm{R}-{ }^{\circ} \mathrm{CH}-\mathrm{O}-\mathrm{CH}_{2}-\mathrm{R}^{\prime}\right)$ [102]. Such $\alpha$-site radicals also are invoked as the products of UV photo-oxidation of the ether group in PADC [103]. As shown in Figure 7, the $\alpha$-radicals (called "A") decompose by transforming the ether function in a carbonyl one, this pathway should thus be an important additional way to understand the loss of 
ether functions in irradiated PADC. Even more interesting is the fact that, based on semi-empirical molecular orbital calculations, it has been proven that the preferred site for hydrogen abstraction in PADC (CR-39 $\left.{ }^{\mathrm{TM}}\right)$ is the C8 site; which is nothing other than the $\alpha$-site of the ether function [104]. Therefore, there is strong evidence demonstrating that the $\alpha$-site of the ether group in PADC is extremely sensible to hydrogen abstraction (leading to the formation of compound " $A$ " in Figure 7). In that way, it is likely that hydrogen radical escaping from the track core further to primary events, then diffusing out of the core, would preferably participate in the damaging of ether functions during the chemical phase of the latent track relaxation, thus confirming that the ether function in PADC is characterized by the largest effective track radius, G-value and bond-breaking cross-section [35].

\subsection{Dynamics of the track structure - Depiction of the latent track in PADC.}

As mentioned by Saleh and Eyal, radiolysis in an ion track is undoubtedly activated by primary reactive species formed upon ion-energy deposition including released electrons, excited atoms, excited molecular fragments, and radicals [105]. A complete description of such dynamical process is a quite harsh task owing to the number and complexity of events participating in the track formation and further relaxation. Nevertheless, with the help of recent studies and according to the analysis proposed above, we can suggest a description of the spatial extension of damages in PADC latent tracks. In contrast with the former paradigm of preferential track etching due to polymer chain scissions, it was shown that the prevalence of main chain scission is in fact not necessary for the creation of defects capable of preferential etching [106]. These recent years a simple model was established by Hnatowicz. The model is based on the assumption that the local composition of the latent track results from chemical reactions of transient degradation products created by an ion passage [107-109]. In this context, radial dependence of the concentrations of low mass fragments, cross-linked structures and intact macromolecules are computed. These parameters are expressed as a function of radial distance from the track center at fixed LET value using specific reactions rates (for different degradation products) and associated G-values. This way, simulated radial etching rates expressed as a function of the distance from the track center successfully mold the trend of experimentally determined radial etch rates. Radial etch-rates are determined by differentiating the function relating effective pore diameters to the respective etching time [106]. Even if the simulation study was applied to polyimide $(\mathrm{PI})$ material $\left(-\left[\mathrm{R}_{1}-\mathrm{CO}-\mathrm{N}\left(\mathrm{R}_{2}\right)-\mathrm{CO}\right]_{\mathrm{n}}-, \rho_{\mathrm{PI}}=1.42 \mathrm{~g} \cdot \mathrm{cm}^{-3}\right)$, a semiquantitative description can be suggested as presented in Figure 9; which in first approximation may

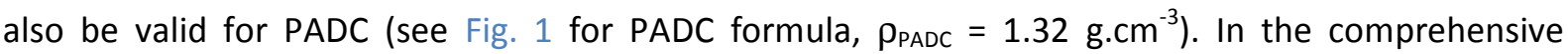
description presented in Figure 9, we added the radial distributions of hydrogen radicals as reported 
by Lewis and Coghlan [97] for PE, PS and PC exposed to He (0.4 MeV), Ne (1 MeV) and $\operatorname{Ar}(1 \mathrm{MeV})$. To scale the figure we used the fact that $\left[\mathrm{H}^{*}\right]->0$ corresponds to the case where the fraction of intact polymer molecules must tend to $100 \%$ and the fraction of crosslinks thus conversely tends to zero. Therefore the radial extension of the track appears in arbitrary units. Simulations by Hnatowicz in PI used $10 \mathrm{MeV} / \mathrm{u}$ Xe ions data.

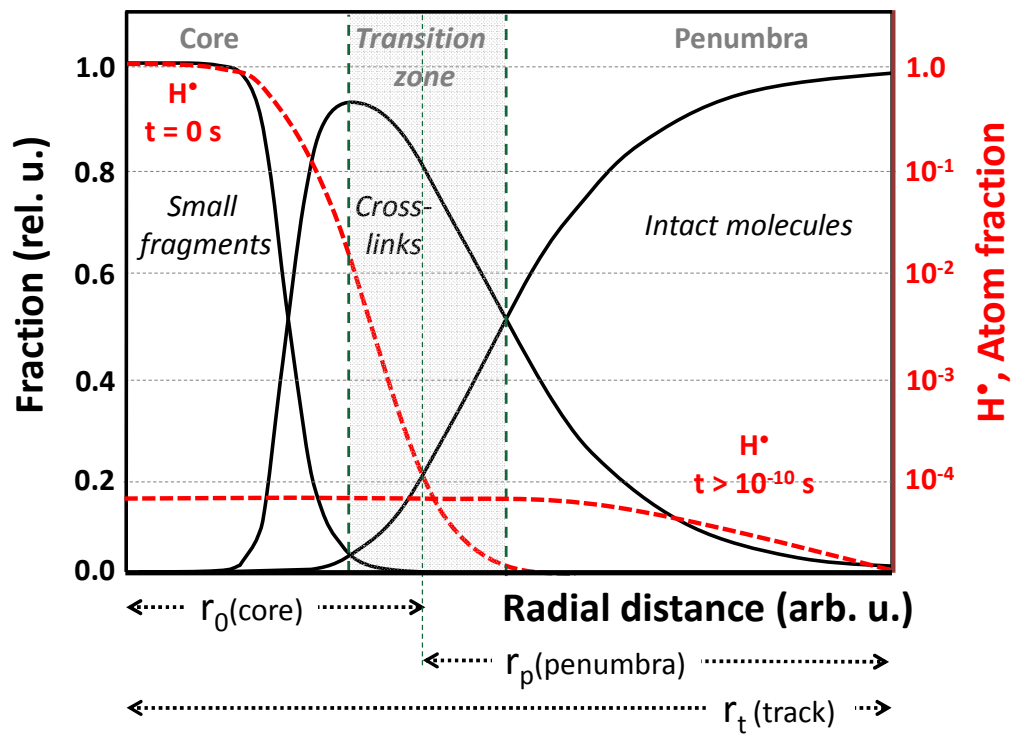

Figure 9: Comprehensive description of the dynamics and spatial evolution of an ion latent track in a polymer. Solid lines reproduce the radial evolution of small fragments, crosslinks and intact molecules with respect to the track center as suggested by Hnatowicz [109] for the case of PI irradiated by energetic ions. Dashed lines reproduce the behavior of the radial distribution of $\mathrm{H}^{*}$ at time zero (Gaussian distribution) and at the end of the physical stage $\left(t>10^{-10} \mathrm{~s}\right)$ as proposed by Lewis and Coghlan [97] for energetic ions slowed down in PE, PS and PC. Computation of the solid lines used radiolytic yields, reaction rates (reactions of transient degradation products) and LET, as for the dashed lines, early time evolution of hydrogen radicals was computed thanks to Fick's law for the diffusion process and to the main reaction rates involving hydrogen radicals (see Fig. 4 for detail) in the studied polymers irradiated at a given particle's LET. Note that for convenience sake, the radial distance appears in arbitrary units due to different polymers used in each of the references (see text for more details about that scale).

The arrangement of curves in Figure 9 allows latent track relaxation dynamics in polymers to be conceived in finer details. Simulations as those in solid lines in Figure 9 have shown good agreement with experimental data [109], especially with measured radial track-etch rates. They provide thus a pertinent approach to describe a latent track at the nanometer-scale. In that way, the model suggests that a transition zone exists (Figure 9) between core and penumbra, were crosslinks are the prevailing species. In that zone the radial etching rate is lowered, even when compared to the bulketch rate of the undamaged polymer material, $V_{B}$ [106]. The concept of such a transition zone between core and penumbra was also suggested by Francisco and coworkers (using the folding track replica technique); namely by analyzing the shape of "new-born" etched tracks in PC [110-111]. Concerning the track core, it corresponds to the zone with the highest density of deposited energy and is therefore the home of harsh molecular damages, in particular bond breaking (formation of molecular fragments) and consecutive release of excited species as well as hydrogen radicals. The 
smaller of those species are prone to move away from the track center in the polymer material. Depending on their reactivity they may react with appropriate sites in the polymer structure. Diffusional and reactive processes have also been taken into account by Lewis and Coghlan [97]. The typical radial dynamics of hydrogen radicals is added in dashed lines to Figure 9. Starting with a Gaussian distribution at time $\mathrm{t}=0$, then taking into account diffusion and the various pathways which consume $\mathrm{H}^{\bullet}$ radicals, the same general feature was found for all studied polymers and ions used [97]. That is to say that $\mathrm{H}^{\bullet}$ atomic fraction at $\mathrm{t}>10^{-10} \mathrm{~s}$ drops by several orders of magnitude at the track center notably due to termination reactions via hydrogen abstraction producing $\mathrm{H}_{2}$, but also by initiating other radical processes, namely propagation reactions and cross-linking. For $t>10^{-10} \mathrm{~s}$, the atomic fraction of $\mathrm{H}^{\circ}$ thus expands over a larger radial distance than the initial one (i.e. at $t=0$ ) due to diffusion. That fraction remains constant over $\sim 2 \mathrm{~nm}$, then finally tends to zero at the maximum radial extension of the track (3-4 nm for the 3 polymers used exposed to $1 \mathrm{MeV}$ Ar or $\mathrm{Ne}$ and 0.4 $\mathrm{MeV} \mathrm{He).} \mathrm{In} \mathrm{the} \mathrm{penumbra} \mathrm{region,} \mathrm{after} \mathrm{passing} \mathrm{by} \mathrm{a} \mathrm{maximum,} \mathrm{the} \mathrm{fraction} \mathrm{of} \mathrm{cross-links} \mathrm{decreases}$ and finally tends to zero, most probably due to saturation effect. It should indeed be noticed that at its maximum the cross-link fraction is close to $100 \%[107,109]$. As a consequence, in the penumbra, remaining hydrogen radicals would thus not largely participate in cross-links, even if they still diffuse away from the core.

When combined with the observations made above and especially those relative to the chemistry of radicals, the dynamics of a latent track presented in Figure 9 allows, at least partly, describing the formation of a latent track in PADC at the molecular scale. In the light of the abovementioned observations, we suggest in Figure 10 the major molecular pathways involved in the formation of an energetic ion track in PADC. Based on the data gathered throughout the present review, we propose that two major (favored) pathways exist by which PADC reacts with molecular or hydrogen radicals during the latent track relaxation. As mentioned above, especially when dealing with $\mathrm{H}^{\bullet}$ characterized by high diffusivity, at the largest radial distances most of the encountered reactions are actually termination, propagation and cross-linking processes. But decomposition of the polymer via bond breaking ( $\beta$-scission) in the vicinity of the ether function (finally forming stable as well as unstable (E) carbonyl moieties, see Figure 7) is also likely to happen. The unstable fragment $E$, with an unpaired electron on the methylene in $\beta$-position of the ether is able to decompose forming $\mathrm{CO}_{2}$ by further breaking the ester carbonate function of PADC (Figure 7). If ether functions appear indeed to be critical targets in PADC, the fate of carbonate ester moieties looks somewhat more complex, requiring multi-step reactions during which the probability of termination, propagation or cross-linking is certainly higher than in the pathways of ether radical decomposition. Such an assertion is in line with recent analyses based on IR spectroscopy analyses of irradiated PADC and low energy electron stimulated desorption $[112,113]$. 


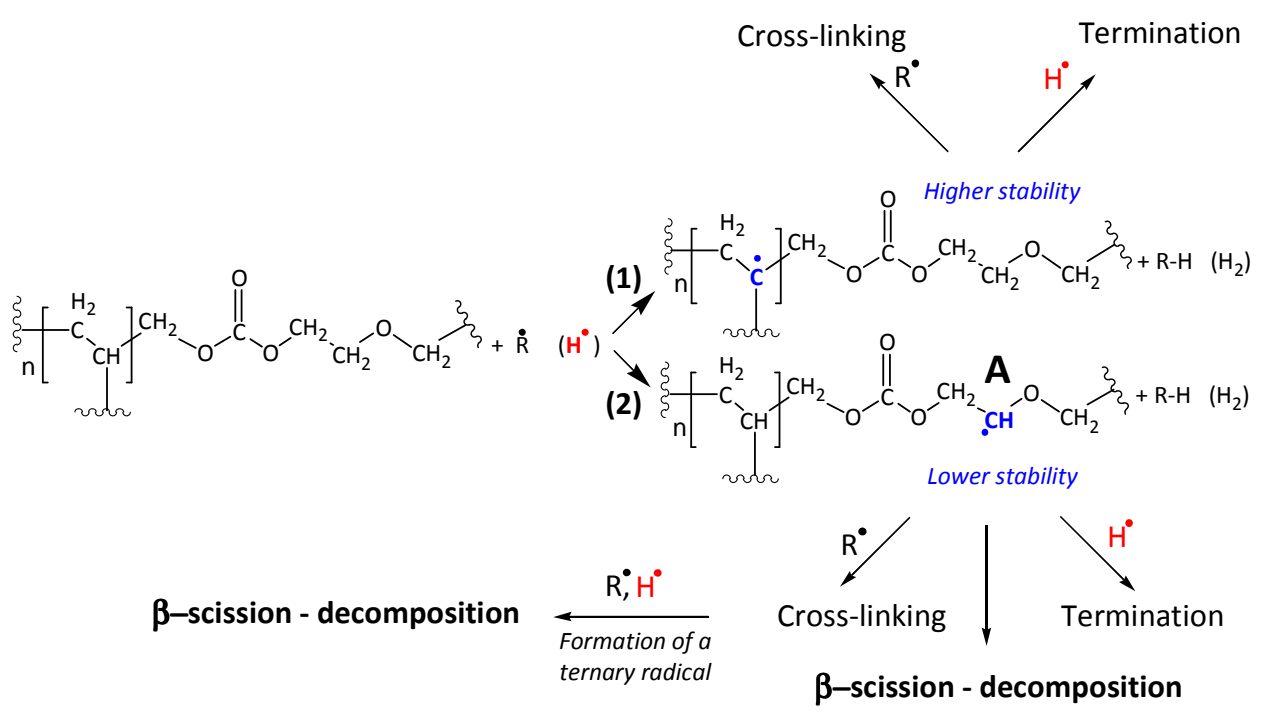

Figure 10: Generalization of the reaction of molecular radicals or hydrogen radicals (in red) on PADC based on the survey undertaken in the present study. Two major pathways are considered. A first one (1) produces the more stable radical (tertiary radical) and a unstable radical (2) both subject to termination or cross-linking reaction. Pathway (2), additionally includes decomposition of the polymer (the detailed description of the decomposition of $(A)$ is in Figure 7). Further to pathway (2) a supplementary tertiary radical can again be carried by the $\alpha$-site of the ether function in PADC and thus decompose following a similar trend (in the bottom left-hand corner). The complete formula of PADC monomer is not shown here for reasons of symmetry of the molecule.

\section{Conclusion and perspectives.}

After having recalled the basic principles of the early processes encountered during the formation of an energetic ion track in a polymer material, we have presented literature data in relation with the formation and further decomposition of hydrogen, alkyl, organic carbonate and ether radicals. For lack of references in direct relation with the formation and further decay of specific radicals in PADC, most of the mechanisms presented herein stem from studies in which surrogate compounds (molecules containing identical chemical functions) carried an unpaired electron after exposure to ionizing radiation. We have shown that several distinct pathways starting from ion-radical intermediates allow $\mathrm{CO}_{2}$ release. There are more pathways involving decomposition products of ether ion radical intermediates than carbonate ones which finally lead to Carbone dioxide release. In addition, it was shown recently that at least two low-energy $(\mathrm{K}<30 \mathrm{eV})$ secondary electrons are necessary to break a carbonate group in PADC [113]. It is quite possible that supplementary decomposition mechanisms exist in irradiated PADC, however those presented herein originate from experimentally identified radicals and available published data. In all pathways presented, $\mathrm{CO}_{2}$ release comes from multi-step mechanisms. In addition to gas release the proposed mechanisms for molecular decomposition arising in irradiated PADC show that cross linking and new 
chemical functions are created within a latent track, especially aldehydes, alcohols and alkenes are possible final products. Cross-links are mainly made up of alkane chains and therefore will behave as hydrophobic regions, conversely, aldehydes and alcohols polar functions will favor hydrophilicity in the latent track. This means that the transition region (Figure 9) between core and penumbra is rather of a hydrophobic nature as the penumbra itself should have hydrophilic character.

This work aimed at placing greater emphasis on the dynamics that takes place further to the primary events (physical phase) of the nuclear track formation in PADC polymer. The present study enables a more general definition of the effective track radius to be suggested; namely that it corresponds to the radial extend to which transient and radical intermediates may diffuse and are likely to react. In PADC, the experimentally observed superiority of effective track radii determined from the intensity of IR absorption lines of ether moieties compared to those relative to ester carbonate or methylene functions can be explained in terms of preferential site for hydrogen abstraction. There is indeed evidence for preferred formation of the alkyloxy radical (on the $\alpha$-site of the ether function) in PADC [104]; the starting point of further decompositions presented in Figure 7. This means in other words that pathway (2) in Figure 10 must not be ignored, at the contrary, it may constitute the major pathway. With this in mind, it is easy to understand why the ether function in PADC is such a critical site and why it is damaged further to hydrogen abstraction up to the external limit of the track penumbra.

An experimental result we didn't speak about must be mentioned. It was demonstrated using small-angle X-ray scattering analyses of $2.64 \mathrm{GeV} U$ ion damage trails in polycarbonate [114] that low concentration of 8-nm diameter bubbles reside in the surrounding track penumbra and those bubbles account for $\sim 13 \%$ of the free volume in an ion-irradiatethere is indeed

PC matrix. Presence of such free volumes might have important consequences especially because, as stated by the authors; the technologically important porous structure is a common characteristic of heavy ion tracks in polymers. As stated by Hossain et al., SAXS also can provide a technology for investigation of the precise shape and size of nano-pores during in situ etching experiments, where also the early evolution of pore formation can be followed [114].

This article may help understanding chemistry of the fundamental aspects of nuclear track formation in PADC and thus provide information to those who are developing new solid state nuclear track detector polymer materials [115].

Lastly, the present overview didn't include a quantitative description of some processes which are likely to take place in irradiated PADC, namely dissociation into various pairs, ion pair formation and dissociative electron attachment (respectively 3, 4, 6, 7, 8 and 9 in Figure 2). Experiments aiming at shedding some new light on those particular processes have at least in part be started recently [113]. 
A last point which was not detailed herein concerns the effect of molecular oxygen on the fate of a latent track in PADC. It was already shown that $\mathrm{O}_{2}$ hardly affects measured G-values for the loss of ether and carbonate chemical functions inside the latent ion tracks in PADC [30]. It is known since long that radio-oxidation processes play an important role in modifying the chemistry of polyethylene, notably by reducing the production of molecular hydrogen $\left(\mathrm{H}_{2}\right)$, double bonds and cross-linking [116]. It was for example shown that irradiation (60Co gamma-rays and $2 \mathrm{MeV}$ electrons) in presence of oxygen of ethylene-propylene-diene monomer (EPDM) and ethylenepropylene rubber (EPR) films favors the formation of ketones, carboxylic acids, hydroperoxides and alcohols [117]; all being of hydrophilic character. These authors also found that post-irradiation degradation at room temperature in the presence of light contributes to the ageing of radio-oxidised films [117].

Further prospective study possibilities may at least include:

- Low energy electron stimulated desorption of PADC surrogate molecules,

- Online and refined ESR analyses of PADC exposed to ionizing radiations,

- Studies on the radio-oxidative processes of latent molecular damages in PADC,

- Confirmation of the formation of cross-links and oxygenated functions in PADC. 


\section{References:}

[1] B.G. Cartwright, E.K. Shirk, P.B. Price, A nuclear-track recording polymer of unique sensitivity and resolution, Nucl. Instrum. Methods 153 (1978) 457-460.

[2] R.M. Cassou, E.V. Benton, Properties and applications of CR-39 polymeric nuclear track detector, Nucl. Track Detect. 2 (1978) 173-179.

[3] G. Espinosa, LI. Font, M. Fromm, A review of the developments in nuclear track methodology as published in the proceedings of the International Conference on Nuclear Tracks in Solids from 1990 to 2008, Radiat. Meas. 50 (2013) 1-6.

[4] Dazhuang Zhou. CR-39 Plastic Nuclear Track Detectors in Physics Research. Nova Science Publishers, 2012.

[5] D.L. Henshaw, Applications of CR-39 nuclear track detector in medicine and technology, Physics in Technology 13 (1982) 266.

[6] A. Malinowska, M. Jaskóła, A. Korman, A. Szydłowski, and M. Kuk, Characterization of solid state nuclear track detectors of the polyallyl-diglycol-carbonate (CR-39/PM-355) type for light charged particle spectroscopy, Rev. Sci. Instrum. 85 (2014) 123505.

[7] D.C. Gautier, J.L. Kline, K.A. Flippo, S.A. Gaillard, S.A. Letzring, and B.M. Hegelich, A simple apparatus for quick qualitative analysis of CR39 nuclear track detectors, Rev. Sci. Instrum. 79 (2008) $10 \mathrm{E} 536$.

[8] S. Kodaira, N. Hasebe, T. Doke, M. Hareyama, K. Sakurai, M. Asaeda, S. Ota, N. Yasuda, H. Tawara, K. Ogura, High performance particle detection system for trans iron isotopes in galactic cosmic rays. Journal of Physics: Conference Series 31 (2006) 221-222.

[9] R.L. Fleischer, P.B. Price and R.M. Walker, Nuclear Tracks in Solids, principles and applications University of California press, Berkeley - Los Angeles - London, 1975.

[10] E. V. Benton, U.S. Naval Radiological Defense Laboratory, TR-68-14, 1968.

[11] R.P. Henke and E.V. Benton, On geometry of tracks in dielectric detectors, Nucl. Instrum. Methods 97 (1971) 483-489.

[12] H.G. Paretzke, E.V. Benton, R.P. Henke, On particle track evolution in dielectric track detectors and charge identification through track radius measurement, Nucl. Instrum. Methods 108 (1973) 7380

[13] G. Somogyi and A. S. Szalay. Track-diameter kinetics in dielectric track detectors, Nucl. Instrum. Methods 109 (1973) 211.

[14] A. Ali and S.A. Durrani. Etched-track kinetics in isotropic detectors. Nuclear Track Detection 1 (1977) 107-121.

[15] M. Fujii and J. Nishimura, Generalized etch-pit equations and their application to analyses of tracks in CR-39 with depth-dependent etching properties, Nucl. Tracks Radiat. Meas. 11 (1986) 25-33. 
[16] M. Fromm, F. Membrey, A. El Rahamany, A. Chambaudet, Principle of light ions micromapping and dosimetry using a CR-39 polymeric detector: Modelized and experimental uncertainties, Nucl. Tracks Radiat. Meas. 21 (1993) 357-365.

[17] B. Dörschel, D. Hermsdorf, U. Reichelt, S. Starke, Computation of etched track profiles in CR-39 and comparison with experimental results for light ions of different kinds and energies, Radiat. Meas. 37 (2003) 573-582.

[18] D. Nikezic, K.N. Yu, Formation and growth of tracks in nuclear track materials, Mater. Sci. Eng. 46 (2004) 51-123.

[19] Fromm, M. Light MeV-ions etching studies in a plastic track detector. Radiat. Meas. 40 (2005) 160-169.

[20] R. Barillon, M. Fromm, A. Chambaudet, R. Katz, J. P. Stoquert, A. Pape, Bond Scission Cross Sections for alpha-particles in Cellulose Nitrate (LR115), Radiat. Meas. 31 (1999). 71-75

[21] R. Barillon, M. Fromm, R. Katz, A. Chambaudet, Chemical bonds broken in latent tracks of light ions in plastic track detectors, Radiat. Prot. Dosimetry 99 (2002) 359-62.

[22] R. Barillon,T. Yamauchi, Chemical bond scission induced by ${ }^{1} \mathrm{H}^{+},{ }^{16} \mathrm{O}^{8+}$, and $\mathrm{p}$-rays in a cellulose nitrate detector, Nucl. Instrum. Methods B 208 (2003) 336-339.

[23] T. Yamauchi, N. Yasuda, T. Asuka, K. Izumi, T. Masutani, K. Oda, R. Barillon, Track core size estimation for heavy ions in CR-39 by AFM and UV methods, Nucl. Instrum. Methods B 236 (2005) 318-322.

[24] T. Yamauchi, Y. Mori, K. Oda, N.Yasuda, H. Kitamura, R. Barillon, Structural modification along heavy ion tracks in poly(allyl diglycol carbonate) films, JAPAN J. Appl. Phys. 47 (2008) 3606-3609.

[25] T. Yamauchi, S. Watanabe, A. Seto, K. Oda, N. Yasuda, R. Barillon, Loss of carbonate ester bonds along Fe ion tracks in thin CR-39 films, Radiat. Meas. 43 (2008) 106-110.

[26] Y. Mori, T. Ikeda, T. Yamauchi, A. Sakamoto, H. Chikada, Y. Honda, K. Oda, Radiation chemical yield for loss of carbonate ester bonds in PADC films exposed to gamma ray, Radiat. Meas. 44 (2009) 211-213.

[27] T. Yamauchi, Y. Mori, A. Morimoto, M. Kanasaki, K. Oda, S. Kodaira, T. Konishi, N. Yasuda, S. Tojo, Y. Honda, R. Barillon, Thresholds of etchable track formation and chemical damage parameters in poly(ethylene terephthalate), bisphenol A polycarbonate, and poly(allyl diglycol carbonate) films at

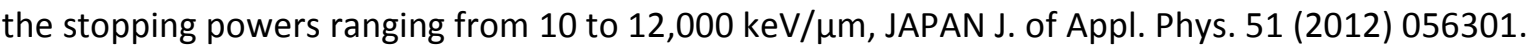

[28] Y.Mori, T. Yamauchi, M. Kanasaki,Y. Maeda, K. Oda, S. Kodaira, T. Konishi, N. Yasuda,R. Barillon, Radiation chemical yields for loss of ether and carbonate ester bonds in PADC films exposed to proton and heavy ion beams, Radiat. Meas. 46 (2011) 1147-1153.

[29] Y. Mori, T. Yamauchi,M. Kanasaki, A. Hattori, Y. Matai,K. Matsukawa, K. Oda, S. Kodaira, H. Kitamura, T. Konishi, N. Yasuda, S. Tojo, Y. Honda, R. Barillon, Greater radiation chemical yields for losses of ether and carbonate ester bonds at lower stopping powers along heavy ion tracks in poly(allyl diglycol carbonate) films, Appl Phys Express 5 (2012) 086401. 
[30] Y. Mori, T. Yamauchi, M. Kanasaki, A. Hattori, K. Oda, S. Kodaira, T. Konishi, N. Yasuda, S. Tojo, Y. Honda, R. Barillon, Vacuum effects on the radiation chemical yields in PADC films exposed to gamma rays and heavy ions, Radiat. Meas. 50 (2013) 97-102.

[31] R. Barillon, Y. Mori, M. Kanasaki, T. Yamauchi, N. Yasuda, Chemical cross sections induced by ions in solid organic detectors: Experimentation and simulation, Radiat. Meas. 50 (2013) 38-42.

[32] Y. Mori, T. Yamauchi, M. Kanasaki, A. Hattori, K. Oda,S. Kodaira, T. Konishi, N. Yasuda, S. Tojo, Y. Honda, R. Barillon, Vacuum effects on the radiation chemical yields in PADC films exposed to gamma rays and heavy ions, Radiat. Meas. 50 (2013) 97-102.

[33] R. Barillon, Y. Mori, M. Kanasaki, T. Yamauchi, N. Yasuda, Chemical cross sections induced by ions in solid organic detectors: Experimentation and simulation, Radiat. Meas. 50 (2013) 38-42.

[34] T. Kusumoto, Y. Mori, M. Kanasaki, T. Ueno, Y. Kameda, K. Oda, S. Kodaira, H. Kitamura, R. Barillon, T. Yamauchi, Yields on the formation of $\mathrm{OH}$ groups and the loss of $\mathrm{CH}$ groups along nuclear tracks in PADC films, Radiat. Meas. 83 (2015) 59-62.

[35] T. Kusumoto, Y. Mori, M. Kanasaki, R. Ikenaga, K. Oda, S. Kodaira, H. Kitamura, R. Barillon,T. Yamauchi, Radiation chemical yields for the losses of typical functional groups in PADC films for high energy protons registered as unetchable tracks, Radiat. Meas. 87 (2016) 35-42.

[36] T. Yamauchi, T. Kusumoto, T. Ueno, Y. Mori, M. Kanasaki, K. Oda, S. Kodaira, R. Barillon, Distinct step-like changes in $G$ values for the losses of typical functional groups in poly(ethylene terephthalate) along boron ion tracks around the detection threshold, Radiat. Meas. 116 (2018) 5154.

[37] R. Katz and E. J. Kobetich, Formation of Particle Tracks. Radiation Effects, 3 (1970), 169-17

[38] R. Katz, Track structure theory in radiobiology and in radiation detection, Nuclear Track Detection 2 (1978) 1-28.

[39] J. Rickards, E.P. Zironi, E. Andrade, Gas ejection from CR-39 under ion bombardment. Radiat. Effects Defects Solids 124 (1992) 1992383-390.

[40] M.A. Malek, C.S. Chong, Diffusion of $\mathrm{CO}_{2}$ gas from X-ray and gamma-ray irradiated CR-39 plastic. In: Proceedings, The Symposium on Nuclear and Related Techniques in Agriculture, Industry and Environmental Studies (NURT'99), Havana, Cuba,26-29 October, 1999.

[41] M.A. Malek, C.S. Chong, Generation of $\mathrm{CO} 2$ in gamma-ray-irradiated CR-39 plastic, Radiat. Meas. 35 (2002) 109-112.

[42] T. Yamauchi, H. Nakai, Y. Somaki, K. Oda, Formation of $\mathrm{CO}_{2}$ gas and $\mathrm{OH}$ groups in CR-39 plastics due to gamma-ray and ions irradiation. Radiat. Meas. 36 (2003) 99-103.

[43] T. Yamauchi, R. Barillon, E. Balanzat, T. Asuka, K. Izumi, T. Masutani, K. Oda, Yields of $\mathrm{CO}_{2}$ formation and scissions at ether bonds along nuclear tracks in CR-39, Radiat. Meas. 40 (2005) 224228.

[44] M. Fujii. R. Yokota T. Kobayashi. H. Hasegawa, Sensitization of polymeric track detectors with carbon dioxide. Radiat. Meas. 25 (1995) 141-144. 
[45] I. Csige, Post-irradiation sensitization of CR-39 track detector in carbon dioxide atmosphere. Radiat. Meas. 28 (1997) 171-176.

[46] M. Fujii, R. Yokota, T. Kobayashi and H. Hasegawa, Effect of vacuum, oxygen and carbone dioxide on the track registration in SR-90 and CR-39. Radiat. Meas. 28 (1997) 61-64.

[47] E. Baradács, I. Csige, I. Rajta, $\mathrm{CO}_{2}$ treatment and vacuum effects in proton beam micromachining of PADC. Radiat. Meas. 43 (2008) 1354-1356.

[48] T. Yamauchi, Y. Mori, H. Chikada, A. Sakamoto, J. Kii, M. Kanasaki, Oda, K., M. Fujii, Sensitization of PADC track detector in carbon dioxide gas, Radiat. Meas. 44 (2009) 9-10.

[49] K.S. Himada, T. Abe, T. limoto and T. Kosako, Sensitization of Solid State Nuclear Track Detector in Carbon Dioxide for Improved Fast Neutron Dosimeter, JAPAN J. Health Phys. 46 (2011) 163-167.

[50] F. d'Errico, D. A.A. de Vasconcelos, R. Ciolini, E. Hulber, Track size distributions in CR-39 neutron dosimeters treated with carbon dioxide. Radiat. Meas. 106 (2017) 607-611.

[51] R. Barillon, T. Yamauchi, Y. Mori,Q. Raffy, A first attempt to simulate oxidization effects on latent track structure in PADC combining the radial dose theory and a radio-oxidation kinetic model, Radiat. Meas. 83 (2015) 1-4.

[52] A. Mozumder. Fundamentals of Radiation Chemistry. Academic Press: San Diego, (1999).

[53] L. Avan, M. Avan, D. Blanc, J.L. Tessier, lonographie DSTN in French, Doin, (1974).

[54] J.E. Turner, Atoms, Radiation, and Radiation Protection. Second ed. Wiley-Interscience, New York (1995).

[55] Z. Zhu, Y. Sun, C. Liu, J. Liu, Y. Jin. Chemical modifications of polymer films induced by high energy heavy ions, Nucl. Instrum. Methods B 193 (2002) 271-277.

[56] J. Stejny, The polymer physics of CR-39 - The state of understanding, Radiat. Prot. Dosimetry 20 (1987) 31-36.

[57] T.A. Gruhn, W.A. Li, E.V. Benton, R.M. Cassou and C.S. Johnson, Proc. $10^{\text {th }}$ Int. Conf. on Solid state nuclear track detectors, Lyon (1979) 291.

[58] K.C.C. Tse, D. Nikezic, K.N. Yu, Comparative studies of etching mechanisms of CR-39 in $\mathrm{NaOH} / \mathrm{H}_{2} \mathrm{O}$ and $\mathrm{NaOH} /$ ethanol. Nucl. Instrum. Methods B 263 (2007) 300-305.

[59] S. Kodaira, D. Nanjo, H. Kawashima, N. Yasuda, T. Konishi, M. Kurano, H. Kitamura, Y.Uchihori, S. Naka, S. Ota, Y. Ideguchi, N.Hasebe, Y. Mori, T. Yamauchi, Mass spectrometry analysis of etch products from CR-39 plastic irradiated by heavy ions, Nucl. Instrum. Methods B 286 (2012) 229-232.

[60] Somogyi, G., Hunyadi, I., Etching properties of the CR-39 polymer nuclear track detector. In: Proceedings of the 10th International Conference on Solid State Nuclear Track Detectors, Lyon, (1979) 443-452.

[61] P.F. Green, A.G. Ramli, S.A.R. Al-Najjar, F. Abu-Jarad, S.A. Durrani, A study of bulk etch rates and track etch rates in CR-39. Nucl. Instrum. Meth. 203 (1982) 551-559. 
[62] R.P. Henke, K. Ogura, E.V. Benton, Standard method for measurement of bulk etch in CR-39. Nucl. Tracks 12 (1986) 307-310.

[63] M. Fromm, F. Membrey, A. Chambaudet, R.F. Saouli, A. Al-Rahamany, A study of CR-39 bulk etch properties under various temperature and concentration conditions to modelise the dissolution rate. Nucl. Tracks Radiat. Meas. 21 (1993) 357-365.

[64] M. Solarz, Y.D. He, Dependence of CR-39 etch rates on concentration of etched products in sodium hydroxide etchant. Nucl. Instrum. Meth. B 100 (1995) 188-190.

[65] Fazal-ur-Rehman, F. Abu-Jarad, M.I. Al-Jarallah, M. Farhat, Comparisons of limitations of three different bulk etch rate measurement methods used for gamma irradiated PM-355 detectors. Radiat. Meas. 34 (2001) 617-623.

[66] M.A. Rana, I.E. Qureshi, Studies of CR-39 etch rates. Nucl. Instrum. Meth. B 198 (2002) 129-134.

[67] C. Papachristodoulou, G. Patiris, K.G. Ioannides, Determination of bulk etch rate for CR-39 nuclear track detectors using an X-ray fluorescence method. Nucl. Instrum. Meth. 264 (2007) 177182.

[68] D. Hermsdorf, M. Hunger, S. Starke, F. Weickert, Measurements of bulk etch rates for poly-allyldiclycol carbonate (PADC) and cellulose nitrate in a broadrange of concentration and temperature of $\mathrm{NaOH}$ etching solution. Radiat. Meas. 42 (2007) 1-7.

[69] E.M. Awad, V.A. Ditlov, M. Fromm, D. Hermsdorf, Description of the bulk etching rate of CR-39 by an extended Arrhenius-like law in increased intervalls of temperature and etchant concentration, Radiat. Meas. 44 (2009) 813-820.

[70] W. Enge, On the question of nuclear track formation in plastic material, Radiat. Meas. 25 (1995) 11-26.

[71] M.A. Rana. Nuclear track formation and skewness of particle trajectories in the target: A new perspective. Nucl. Instrum. Methods B 266 (2008) 3487-3490.

[72] C.D. Lane and T.M.Orlando, Inelastic electron scattering and energy-selective negative ion reactions in molecular films on silicon surfaces, Appl. Surf. Sci. 253 (2007) 6646-6656.

[73] J.W. McConkey, C.P. Malone, P.V. Johnson, C. Winstead, V. McKoy, I. Kanik, Electron impact dissociation of oxygen-containing molecules-A critical review, Physics Reports. 466 (2008) 1-103.

[74] H.Nikjoo, S.Uehara, D.Emfietzoglou, F.A. Cucinotta, Track-structure codes in radiation research. Radiat. Meas. 41 (2006) 1052-1074.

[75] H. Palmans et al. Future development of biologically relevant dosimetry, Br. J. Radiol. 88 (2015) 20140392.

[76] M. Fromm, M.A. Quinto, P.F. Weck, C. Champion, Low energy electrons and swift ion track structure in PADC, Radiat. Phys. and Chem. 115 (2015) 36-42.

[77] L. Sanche, Dissociative Attachment in Electron Scattering from Condensed O2 and CO, Phys. Rev. Lett. 53 (1984) 1638 
[78] C.R. Arumainayagam, H.-L. Lee, R.B. Nelson, D.R. Haines, R.P. Gunawardane, Low-energy electron-induced reactions in condensed matter, Surf. Sci. Reports 65 (2010) 1-44.

[79] Carbon-Centered Free Radicals and Radical Cations: Structure, Reactivity Edited by Malcolm D.E. Forbes, John Wiley and sons, Inc. (2010).

[80] A. Chapiro, Chemical modifications in irradiated polymers, Nucl. Instrum. Methods B 32 (1988) 111-114.

[81] H. Mitsui and F. Hiosoi, $\gamma$-radiation-induced cross-linking of polyethylene, Polym. J. 4 (1973) 7986.

[82] C. Darraud-Taupiac, J. L. Decossas, J.C. Vareille and J. Stejny, Study of free radicals in poly(diethylene glycol bis(allyl carbonate)) irradiated by $\gamma$ rays, Polymer 36 (1995) 3251-3254.

[83] S.E. Shiryaeva, I.S. Sosulin, E.V. Saenko, V.I. Feldman, lon-radical intermediates of the radiationchemical transformations of organic carbonates, Radiat. Phys. and Chem. 124 (2016) 19-25.

[84] U. Ravasio, A. Buttafava, M. Mariani, D. Dondi, A. Faucitano, EPR and ab-initio study on the solid state radiolysis of aliphatic and aromatic polyesters, Polymer Degradation and Stability 93 (2008) 1031-1036.

[85] N.S. Ganghi, D.N.R. Rao, M.C.R. Symons, Radical cations of organic carbonates, trimethyl borate and methyl nitrate, J. Chem. Soc. Faraday Trans. 182, (1986) 2367-2376.

[86] N.X. Thang and T.T. Doan, Structure effect in response function of CR-39 detector, Radiat. Meas. 25 (1995) 185-187.

[87] M.A. Malek, A. Renreng, C.S. Chong, Mechanistic model for bond scission in a polymeric system by radiation, Radiat. Phys. and Chem. 60 (2001) 603-607.

[88] A. Faucitano, A. Buttafaya, F. Martinotti, P. Ferloni and A. Magistris, The mechanism of gammaradiolysis of polymethylene, polypropylene and poly-n-butylene oxides: An ESR investigation, Radiat. Phys. Chem. 40 (1992) 347-355.

[89] A. Bernas, A. Chambaudet, J. Roncin, Sur la formation des traces latentes d'ions lourds et les dégâts chimiques induits par les faisceaux d'ions ou d'électrons dans le polymethacrylate de méthyle, Int. J. Radiat. Phys. Chem. 7 (1975) 447-455.

[90] Z. Chang, J.A. LaVerne, The gases produced in gamma and heavy-ion radiolysis of poly(methyl methacrylate), Radiat. Phys. and Chem. 62 (2001) 19-24.

[91] C.P. Ennis and R.I. Kaiser, Mechanistical studies on the electron-induced degradation of polymethylmethacrylate and Kapton, Phys. Chem. Chem. Phys. 12 (2010) 14902-14915.

[92] I. Plante, A. Ponomarev, F.A. Cucinotta, 3D visualisation of the stochastic patterns of the radial dose in nano-volumes by a Monte Carlo simulation of HZE ion track structure, Radiat. Prot. Dosimetry 143 (2011) 156-61.

[93] J. L. Magee and A. Chatterjee, Radiation chemistry of heavy-particle tracks, 1. General considerations, J. Phys. Chem. 84 (1980) 3529-3536. 
[94] H.G. Paretzke, Radiation track structure theory. In Kinetics of Nonhomogeneous Processes (G. R. Freeman, Ed.), Wiley, New York, (1987) 89-170.

[95] E.H. Lee, Ion-beam modification of polymeric materials - fundamental principles and applications. Nucl. Instrum. Methods B 151 (1999) 29-41.

[96] J.C. Vareille, J.L. Decossas and J.L. Tessier, Model of ion latent tracks in a polymer. Radiat. Prot. Dosimetry, 13 (1985) 49-52.

[97] M.B. Lewis, W.A. Coghlan, lon-track reaction-rate model for hydrogen production from polymers, J. Nucl. Mater. 228 (1996) 302-317.

[98] P. Apel, A. Schulz, R. Spohr, C. Trautmann, V. Vutsadakis, Track size and track structure in polymer irradiated by heavy ions, Nucl. Instrum. Methods B 146 (1998) 468-474.

[99] T.A. Tombrello, Predicting latent track dimensions, Nucl. Instrum. Methods B 94 (1994) 424-428.

[100] J.H. O'Donnell, Radiation Chemistry of Polymers, The Effects of Radiation on High-Technology Polymers. Chapter 1, pp 1-13. ACS Symposium Series, 381 (1989).

[101] Radiation Chemistry of Organic Compounds, Pergamon Press, London \& New York, (1960).

[102] T. Haraldson, M. Johansson and A. Hult, The effects of abstractable hydrogen in radical photopolymerization of maleate/vinyl ether monomers studied with EPR and photo-RTIR. J. Polym. Sci. Part A 48 (2010) 2810-2816.

[103] K.C.C. Tse, F.M.F. Ng, K.N. Yu, Photo-degradation of PADC by UV radiation at various wavelengths. Polym. Degrad. Stabil. 91 (2006) 2380-2388.

[104] A. Qureshi, C. H. Schiesser and D. H.Solomon, Investigations into free radical polymerizations of allyl carbonates-II. An MNDO study of hydrogen atom abstraction by hydroxyl radical, Eur. Polym. J. 32 (1996) 85-89.

[105] S. A. Saleh, Y. Eyal, Morphology of track cores and halos created by swift uranium ions in polycarbonate, Nucl. Instrum. Methods B 236 (2005) 81-87.

[106] P.Y. Apel, A.Y. Didyk, A. G. Salina, Physico-chemical modification of polyolefins irradiated by swift heavy ions, Nucl. Instrum. Methods B 107 (1996) 276-280.

[107] V. Hnatowicz, Role of scission and cross-linking in latent track formation in polymers. Nucl. Instrum. Methods B 209 (2003) 145-148.

[108] V. Hnatowicz, Simple kinetic model of ion induced gas emission from polymers, Nucl. Instrum. Methods B 215 (2004) 162-168.

[109] V. Hnatowicz, J.Vacik, P.Y.Apel, On the structure of etched ion tracks in polymers. Radiat. Phys. and Chem. 121 (2016) 106-109.

[110] O.A. Bernaola, G. Saint Martin, S.M. Azpiazu Garrido, Submicroscopic analysis of damage structure in nuclear tracks, Radiat. Meas. 41 (2006) 247-252. 
[111] D.H. Francisco, L. Vanni, O.A. Bernaola, G. Saint Martin, A. Filevich. Radial variation of track damage in polycarbonate. Nuclear Instruments and Methods in Physics Research B 218 (2004) 461465

[112] T. Kusumoto, Y. Mori, M. Kanasaki, K. Oda, S. Kodaira, Y. Honda, S. Tojo, R. Barillon, T. Yamauchi, Sudden increase of the radiation chemical yield for loss of carbonate ester in PADC detector where the track overlapping of $28 \mathrm{MeV}$ electrons becomes significant, JPS Conf. Proc. 11 (2016) 010001

[113] T. Kusumoto, M. Fromm, P. Cloutier, A.D. Bass, L. Sanche, R. Barillon, T. Yamauchi, Elucidation of the two-step damage formation process of latent tracks in poly(allyl diglycol carbonate), PADC: role of secondary low-energy electrons, J. Phys. Chem. C 122 (2018) 21056-21061.

[114] U.H. Hossain, M.D. Rodriguez, D. Schauries, A. Hadley, M. Schleberger, C. Trautmann, S. Mudie, P. Kluth, SAXS investigation of un-etched and etched ion tracks in polycarbonate, Nucl. Instrum. Methods B 409 (2017) 293-297.

[115] D.G. Naik, V.S. Nadkarni, Poly (triallyl phosphate) and its copolymers with allyl diglycol carbonate as Solid State Nuclear Track detectors. Des. Monomers Polym. 19 (2016) 643-649. doi: 10.1080/15685551.2016.1187445

[116] R.M. Black and A. Charlesby, The oxidation of irradiated polyethylene-I Radio-oxidation, Int. J. Appl. Radiat. Isotopes 959 (1959) 126-133.

[117] A. Rivaton, S. Cambon, J.-L. Gardette, Radiochemical ageing of EPDM elastomers. 2. Identification and quantification of chemical changes in EPDM and EPR films c-irradiated under oxygen atmosphere, Nucl. Instrum. Methods B 227 (2005) 343-356. 